Editorial

\title{
Impact of River Hydrology on Hydraulic Engineering and Hydropower
}

\author{
Alberto Bianchi (D) \\ Dipartimento di Ingegneria Civile e Ambientale, Politecnico di Milano, 20133 Milano, Italy; \\ alberto.bianchi@polimi.it
}

check for

updates

Citation: Bianchi, A. Impact of River Hydrology on Hydraulic Engineering and Hydropower. Water 2021, 13,

3165. https://doi.org/10.3390/ w13223165

Received: 11 October 2021

Accepted: 3 November 2021

Published: 10 November 2021

Publisher's Note: MDPI stays neutral with regard to jurisdictional claims in published maps and institutional affiliations.
Keywords: climate change; river hydrology; hydrological modeling; river engineering; hydroelectric power plants; hydropower production; run-of-the-river plants; mini-hydropower; economic feasibility indices; circular economy; sustainable development

The current theme is the impact that the awareness of the non-stationarity of hydrological phenomena, and of river hydrology in particular, has on hydraulic engineering and hydropower. This goes hand in hand with the awareness of the non-stationarity of the climate.

Closely linked to climate change is the growing need for environmental protection and more generally for sustainable development also from a social point of view. Future river engineering works should be conceived, designed, built and managed in view of these future scenarios, and their feasibility should no longer be assessed only in economic terms, but through parameters and indices that quantify their sustainability and the contribution they make to the improvement of the living conditions of the individual and the human community.

Six full research articles are published in this Special Issue. Although the authors are mostly Italian and mainly from the Department of Civil and Environmental Engineering of the Politecnico of Milan, the topics covered, always very specialized, range worldwide including hydroelectric problems in Italy, but also in the Himalayas in Nepal, Ethiopia and California, enriched by the contributions of other researchers of the Politecnico of Milan, from other Italian Research Bodies and from Californian Universities and Bodies.

Although the hydropower sector is only one of the fields of hydraulic engineering affected by river hydrology, five of the six articles deal directly with hydroelectric plants.

Articles by Tommaso Duratorre et al. [1], Daniele Bocchiola et al. [2], Giovanni Martino Bombelli et al. [3] and Anita Raimondi et al. [4] investigate the effects of the evolution of river hydrology and energy demand and its price on the future management of hydroelectric plants and their future production as a consequence of the different scenarios of climate change in different parts of the world.

Han Guo et al. [5] develop an enhanced forecasting method using a process-based hydrological model and spatially distributed wireless sensor data that offers more accurate runoff forecasts than statistical forecasting models based on regressing summer flow against spring snow water equivalent, precipitation, and antecedent runoff in the Sierra Nevada in California and other seasonally snow-covered mountains and show the increase in energy value with the enhanced forecasting informing reservoir operations.

Finally, the article by Paola Faggian [6] develops the more general theme of climatic extremes, consecutive dry days and extreme precipitations, in Italy.

In the relatively small catchments in the Italian Alps, up to the end of the century, authors foresee that precipitation would show uncertain patterns with the reduction in the snowfall and increase in rainfall and the exacerbate climatic extremes in the coming decades as the main factors affecting the modified hydrological regime. 
Meanwhile, reduction of the ice volume in 2100 up to more than $90 \%$ vs. current ice volume will occur with a subsequent large, if not total, reduction of ice melt contribution to stream flows, with ice melting unable to offset the precipitation decrease. Snow melt, now covering in some basins up to nearly half of the stream flows yearly, would also be largely reduced.

The stream flows will decrease on average at 2100, with potential for increased flows in fall and winter, and a large decrease in summer. The average annual stream flows for hydropower production decreases along the century under these scenarios and the incoming discharges at the plant would erratically vary. Worse conditions than now may occur, especially for run of the river plants with small drainage areas.

Hydropower production significantly depends on monthly discharge patterns, with mostly positive variations and its change driven by the excessive capacity of the plants, especially that of their reservoirs. Energy production and revenues, being affected also by the changing price of the energy, at half-century may increase, while at the end of the century, under the warmest scenario, its decrease is consistently projected, in spite of a possible projected increase on average.

It is a matter of the fact that hydroelectric plants are called on to play an increasing role in satisfying the demand for energy from renewable sources, and reservoirs for hydroelectric purposes can play an important function in compensating for the differences between the demand and supply of electric power; but many other sectors of hydraulic engineering with potentially enormous impacts on the environment, such as irrigation schemes and multipurpose reservoirs operations, interact with the river hydrology and have not been touched upon in this Special Issue.

Nevertheless, taking cues from the articles in this issue, it is possible to draw more general considerations on the intense environmental changes taking place in terms of climate and the increasingly decisive human influence on environmental systems including the river hydrological regime.

In the face of these changes, the modeling tools and traditional study approaches available to experts are showing all their inadequacy.

In the hydrological field, modeling has developed increasingly effective means in constructing hydrological models which to date have reached very high levels of spatial and temporal accuracy. However, the anthropic factor in environmental systems can no longer be ignored. Therefore, the need arises to create tools capable of capturing and integrating human influence on hydrological systems into environmental models.

Being able to model decision-making processes is essential to try to understand how the entire river basin, of which the anthropogenic component is now a part, could react to the major climatic and social events taking places, such as the further rise in the Earth's temperature, political conflicts, and migratory phenomena. In this way, it will be possible to identify management policies that are economically, socially, and environmentally sustainable and supportive in a holistic vision of how the system works and evolves.

Funding: This research received no external funding.

Institutional Review Board Statement: Not applicable.

Informed Consent Statement: Not applicable.

Conflicts of Interest: The author declares no conflict of interest.

\section{References}

1. Duratorre, T.; Bombelli, G.M.; Menduni, G.; Bocchiola, D. Hydropower Potential in the Alps under Climate Change Scenarios. The Chavonne Plant, Val D'Aosta. Water 2020, 12, 2011. [CrossRef]

2. Bocchiola, D.; Manara, M.; Mereu, R. Hydropower Potential of Run of River Schemes in the Himalayas under Climate Change: A Case Study in the Dudh Koshi Basin of Nepal. Water 2020, 12, 2625. [CrossRef]

3. Bombelli, G.M.; Tomiet, S.; Bianchi, A.; Bocchiola, D. Impact of Prospective Climate Change Scenarios upon Hydropower Potential of Ethiopia in GERD and GIBE Dams. Water 2021, 13, 716. [CrossRef] 
4. Raimondi, A.; Bettoni, F.; Bianchi, A.; Becciu, G. Economic Sustainability of Small-Scale Hydroelectric Plants on a National Scale-The Italian Case Study. Water 2021, 13, 1170. [CrossRef]

5. Guo, H.; Conklin, M.; Maurer, T.; Avanzi, F.; Richards, K.; Bales, R. Valuing Enhanced Hydrologic Data and Forecasting for Informing Hydropower Operations. Water 2021, 13, 2260. [CrossRef]

6. Faggian, P. Future Precipitation Scenarios over Italy. Water 2021, 13, 1335. [CrossRef] 